\title{
DESENVOLVIMENTO SUSTENTÁVEL COM PERSPECTIVA DE GÊNERO - BRASIL, MÉXICO E CUBA: MULHERES PROTAGONISTAS NO MEIO RURAL
}

\author{
Teresa Kleba Lisboa \\ Universidade Federal de Santa Catarina \\ Mailiz Garibotti Lusa \\ Universidade Federal de Alagoas
}

\begin{abstract}
Resumo: Este artigo traz para o debate as concepções de alguns autores sobre desenvolvimento sustentável e, a partir de uma pesquisa realizada em três países (Brasil, México e Cuba), ressaltamos o protagonismo das mulheres camponesas junto à produção de alimentos e ao manejo de recursos naturais; a força dos movimentos de mulheres camponesas na conquista de direitos; e a decisiva participação das mulheres na definição e propostas de políticas públicas que garantam a equidade de gênero no meio rural. Uma breve análise comparativa nos leva a deduzir que o modelo de desenvolvimento, nos três países, ainda prioriza a figura masculina no espaço agrícola, no que se refere à titularidade da terra, ao acesso à crédito e à aquisição de equipamentos ou outros recursos materiais. Sugere-se que, tanto em Cuba, um país socialista, como no México e Brasil, países capitalistas, os pressupostos das políticas sociais direcionadas para as trabalhadoras rurais devem levar em conta as necessidades básicas das mulheres camponesas para garantir um desenvolvimento mais humano e sustentável. Palavras-chave: gênero e meio ambiente; desenvolvimento sustentável; políticas públicas; necessidades básicas.
\end{abstract}

O presente artigo fundamenta-se em dados coletados através de pesquisa' realizada junto a instituições que trabalham com a questão agrária e junto a grupos organizados e/ ou movimentos de mulheres agricultoras em três diferentes países: Brasil (Brasília e Chapecó/

Copyright @ 2010 by Revista Estudos Feministas.

' Pesquisa aprovada pela Secretaria de Políticas Públicas para Mulheres em parceria com o CNPq. Edital MCT / CNPq / SPM-PR / MDA No 57/2008 
SC), Cuba (Havana), México (Distrito Federal e San Cristóbal de las Casas), com interesse centrado na abordagem do desenvolvimento sustentável com perspectiva de gênero, apontando políticas públicas a partir das necessidades básicas das mulheres do campo. O levantamento de dados ocorreu de setembro de 2008 a dezembro de 2009 , através de visitas pré-agendadas às instituições, organizações, docentes, militantes e integrantes de núcleos de estudos que trabalham com a temática, nas cidades acima mencionadas; participação em eventos, feiras agroecológicas, palestras e conversas informais com mulheres agricultoras. Além disso, foram realizadas entrevistas com lideranças que se destacam junto aos Movimentos Campesinos nos três países, a saber: três integrantes do Movimento de Mulheres Camponesas (Brasil), a diretora e o secretário executivo da Associación Mexicana de Mujeres Organizadas em Red - AMMORA e Red Nacional de Promotoras y Asesoras Rurales - REDPAR (México); uma das coordenadoras da Federación de Mujeres Cubanas - FMC e a responsável pelo setor de assuntos externos da Asociación Nacional de Agricultores Pequeños - ANNAP (Cuba).

A pesquisa teve como norte as seguintes questões: a) o debate sobre a importância do papel das mulheres camponesas no processo de desenvolvimento sustentável tem sido devidamente publicizado?, b) que tipos de necessidades básicas fazem parte do cotidiano de trabalho das mulheres camponesas, e c) quais as políticas públicas que contemplam essas demandas e que propostas podem ser apontadas para a implementação das mesmas?

Segundo dados da ONU, $70 \%$ dos pobres do mundo vivem no meio rural e são fundamentalmente pequenos agricultores e agricultoras, integrantes de comunidades indígenas, famílias que vivem da pesca, do pastoreio ou trabalhadores rurais sem propriedade da terra. Nos projetos de extensão desenvolvidos com mulheres nas comunidades da periferia urbana de Florianópolis/SC, temos nos deparado com o crescente aumento dos fluxos migratórios do campo para a cidade, consequência da agudização da pobreza no meio rural. O esvaziamento das áreas rurais brasileiras é um fato. Conforme dados do IBGE, 2000, no último período intercensitário constatou-se uma taxa negativa de $1,31 \%$, ou seja, houve uma perda populacional da área rural brasileira de 246.720 migrantes no período 1995-2000. A maioria das famílias sai do campo porque não recebe apoio nem subsídios para lá permanecer.

Com base nesse tipo de constatação, passamos a nos indignar com o descaso do poder público em relação às famílias que possuem pequenas propriedades e, principalmente, com a falta de reconhecimento e valorização do protagonismo que as mulheres exercem na produção de alimentos para toda a nação. Trouxemos para a pauta de debates o tipo de desenvolvimento que está em vigência, que não considera as necessidades humanas, que não implementa políticas públicas no campo e que discrimina as mulheres como protagonistas, como sujeitos sociais específicos, com necessidades, interesses, contribuições, aspirações e problemáticas próprias.

Aproximando-nos de autores e autoras que trabalham com as propostas de desenvolvimento humano, ${ }^{2}$ desenvolvimento sustentável, ${ }^{3}$ desenvolvimento à escala humana, ${ }^{4}$ e ecofeminismo, ${ }^{5}$ constatamos que os/as mesmos/as são unânimes em afirmar que as mulheres desempenham um papel fundamental no processo de desenvolvimento porque são elas que produzem a maior parte dos alimentos consumidos em todo o mundo.

\footnotetext{
2 Marcela LAGARDE, 1996.

${ }^{3}$ Ignacy SACHS, 2008.

${ }^{4}$ Manfred MAX-NEEF; Antonio ELIZALDE; Martín HOPENHAYN, 1986.

${ }^{5}$ Vandana SHIVA, 1993.
} 
Shiva ${ }^{6}$ lembra que a finalidade do desenvolvimento seria criar bem-estar e abundância para todas as pessoas, mas para a maior parte dos habitantes do Terceiro Mundo, o atual tipo de desenvolvimento só trouxe degradação ambiental e pobreza. A autora chama a atenção para a desvalorização e invisibilidade do papel das mulheres e das crianças na garantia do sustento das famílias e afirma que a contribuição das mulheres e das crianças para a economia de mercado é totalmente negligenciada e negada.

Estudos feitos pelo Instituto Interamericano de Cooperação para a Agricultura IICA, ${ }^{7}$ em 2003, apontam a agricultura familiar como estratégia de sobrevivência, abrangendo, basicamente, a força de trabalho feminina e a das crianças. São as agricultoras que vão preservar as habilidades necessárias aos diferentes tipos de cultivos da alimentação básica (milho, mandioca, feijão) de cada país, a criação de diversas espécies de animais de pequeno porte (ovinos, suínos, caprinos), bem como o manejo do gado leiteiro no espaço da agricultura familiar ou comunitária. Por esse caminho, o Instituto registra que as mulheres "detêm habilidades e experiências necessárias à condução de um processo de desenvolvimento humano local sustentável", 8 pois são as que mais contribuem para a preservação da biodiversidade no pequeno lote de terra, por intermédio da seleção de espécies de sementes e preservando a cultura dos quintais.

Trabalhando na perspectiva do que a autora chama de "um desenvolvimento mais humano", Marcela Lagarde ${ }^{9}$ adverte que, se as mulheres fossem incluídas no processo de desenvolvimento, as aldeias, países e todas as nações teriam bons níveis de qualidade de vida e condições de sobrevivência! Porém, ao excluir pelo menos a metade da população do acesso aos bens e aos espaços, o atual modelo de desenvolvimento atribui prioridade aos interesses masculinos, gerando desigualdade e pobreza.

Uma nova concepção de desenvolvimento, para Lagarde, surge como produto de uma visão feminista, com perspectiva de gênero, e implica uma ruptura com todas as concepções anteriores de desenvolvimento, bem como a irrupção no campo teórico-político do novo paradigma em que se inscreve o feminismo. Por isso, a perspectiva de gênero não seria para a autora somente um novo enfoque, mas uma nova concepção de mundo e, no que se refere ao desenvolvimento, este deveria:

incluir as necessidades das mulheres e considerá-las prioritárias; modificar as necessidades humanas dos homens, uma vez que muitas delas concretizam formas e mecanismos de opressão sobre as mulheres; modificar as necessidades comunitárias, nacionais e mundiais ao requerer um caminho de desenvolvimento com sentido mais humano, ou seja, centrado na escala humana. ${ }^{10}$

Partindo desse pressuposto, o paradigma do 'desenvolvimento humano', apoiado em seus princípios de sustentabilidade, equidade, produtividade e empoderamento, teria como objetivo atender as necessidades básicas das pessoas e, para tanto, requer uma cobrança do Estado, em relação às políticas públicas que venham ao encontro das carências e privações das mulheres que, na maioria das situações, são as responsáveis pelo sustento das unidades domésticas.

\footnotetext{
${ }^{6}$ SHIVA, 1993, p. 96

7 O Instituto Interamericano de Cooperação para a Agricultura - IICA é o organismo especializado em agricultura do Sistema Interamericano, criado por resolução do Conselho Diretor da União Pan-Americana em outubro de 1942. Os objetivos do IICA são estimular, promover e apoiar os esforços dos Estados Membros para alcançar seu desenvolvimento agrícola e o bem-estar rural. Conforme site: <http://www.iica.org.br>. ${ }^{8}$ IICA, 2003, p. 59.

9 LAGARDE, 1996, p. 163.

${ }^{10}$ LAGARDE, 1996, p. 123.
} 
Da mesma forma, Ignacy Sachs ${ }^{11}$ coloca como eixos da proposta de um desenvolvimento sustentável, "desejável e possível" para o Terceiro Mundo: oportunidade de trabalho para todos, inclusão social, políticas públicas, distribuição de renda, igualdade, equidade e solidariedade. O autor propõe que o objetivo maior do desenvolvimento seja a promoção da igualdade e a maximização das vantagens daqueles que vivem nas piores condições, reduzindo a pobreza, contraditoriamente desnecessária, no nosso mundo de abundância. Equidade, para Sachs, significa o tratamento desigual dispensado aos desiguais, de forma que as regras do jogo favoreçam os participantes mais fracos e incluam ações afirmativas que os apoiem. Sachs apresenta os cinco pilares do desenvolvimento sustentável: o social, o ambiental, o territorial, o econômico e o político, e diz que, para alcançá-los, são necessárias estratégias a curto e médio prazos, propostas de políticas públicas que requerem um amplo debate social, inclusive, imediata mudança de paradigma.

Nessa mesma linha de pensamento, Max-Neef ${ }^{12}$ associa o processo de "desenvolvimento alternativo" com o que ele chama de "empoderamento das mulheres", propondo a desconstrução do paradigma de desenvolvimento centrado na riqueza, para incluir a afirmação, a valorização e a capacitação das mulheres que ao longo da história foram mantidas como invisíveis e não como sujeitos do desenvolvimento. O autor parte do pressuposto de que o 'desenvolvimento' tem a ver com pessoas e não com objetos, rompendo com a lógica que 'coisifica' as pessoas e as relações. Nesse sentido, para ele, é imperativo considerar a participação das mulheres no processo de desenvolvimento, pois são as mulheres as que mais se preocupam com a sobrevivência.

Em levantamento realizado sobre "escolas de estudos e ativismos feministas do meio ambiente", Dianne Rocheleau, Barbara Thomas-Slayter e Esther Wangari ${ }^{13}$ nomeiam e caracterizam as seguintes escolas: a ecofeminista; a ambientalista feminista; a feminista socialista; a pós-estruturalista feminista; e a ambientalista. Partindo da perspectiva de gênero e meio ambiente enfocada por essas escolas, elas propõem um novo marco conceitual que denominam "ecologia política feminista". A primeira preocupação das autoras é com a ecologia política que se centra na distribuição desigual do acesso aos recursos e do controle dos mesmos, fatores que dependem tanto da dimensão de classe como da de etnia. Segundo as autoras

a ecologia política feminista considera o gênero como uma variável crítica que conforma o acesso aos recursos, e seu controle, ao interagir com a classe, a casta, a raça, a cultura e a etnicidade para assim, dar forma a processos de câmbio ecológico, à luta de homens e mulheres para sustentar formas de subsistência ecologicamente viáveis e às expectativas que qualquer comunidade possui em relação a um desenvolvimento sustentável. ${ }^{14}$

Essa proposta sugere que a política ambiental e o ativismo de base devem ser estruturados de acordo com o enfoque de gênero, uma vez que a recente onda de participação das mulheres em lutas coletivas, a favor dos recursos naturais e das questões ambientais, tem contribuído para a redefinição das suas identidades, dando maior visibilidade ao significado de gênero e à natureza dos problemas ambientais.

As autoras acreditam que existem diferenças de gênero 'reais', e não imaginadas, nas experiências que homens e mulheres possuem em relação à natureza e às

\footnotetext{
1 SACHS, 2008, p. 21.

12 MAX-NEEF, 2003, p. 02

${ }^{13}$ ROCHELEAU; THOMAS-SLAYTER; WANGARI, 2004.

${ }^{14}$ ROCHELEAU; THOMAS-SLAYTER; WANGARI, 2004, p. 345
} 
responsabilidades e interesses relacionados ao meio ambiente. Portanto, no entender delas, a proposta da ecologia política feminista examina a intersecção entre gênero e meio ambiente através da lente de três temas polêmicos: a ciência estruturada com base no gênero (domínio dos homens); os direitos estruturados com base no gênero (tanto à propriedade como ao processo de manejo dos recursos); e as organizações e atividades políticas que também dependem do gênero. A crescente participação e envolvimento das mulheres nas lutas ambientais permitirão que elas mesmas possam reconceitualizar e redefinir o que é políitico, o que é meio ambiente, o que é justo e equitativo, enfim, contribuir para um desenvolvimento sustentável, a partir de suas demandas e necessidades.

\section{0 enfoque de gênero nas propostas de desenvolvimento: são as necessidades das mulheres camponesas distintas daquelas dos homens?}

Pensar em desenvolvimento sustentável com perspectiva de gênero implica formular propostas de intervenção no campo com base na equidade de gênero, prover instrumentos para a análise político-institucional, ou seja, realizar propostas de mudança institucional com o objetivo mais igualitário e democrático. Nesse sentido, nossa pesquisa constatou algumas situações.

Na região de Chiapas (México), por exemplo, ocorre uma significativa desigualdade entre homens e mulheres no que se refere ao acesso e titularidade da terra. De acordo com dados do PROCEDE, ${ }^{15}$ enquanto os homens constituem $88 \%$ do total de titulares com direitos agrários, a proporção de mulheres com direito a terra é somente de $12 \%$ e, mesmo assim, nem todas possuem o título em seu nome. Além disso, a "Ley de Aguas Nacionales"16 não reconhece as mulheres como usuárias de água, somente como consumidoras. Para a referida Lei, são usuários aqueles que, de maneira formal, possuem um título de propriedade e de concessão para o uso de água. O não reconhecimento das mulheres como produtoras também as exclui das instâncias de tomada de decisões sobre o uso dos recursos naturais.

De acordo com publicação dos resultados do Projeto "Cuba, Mujeres y Hombres y Desarrollo Sostenible", financiado pelo PNUD, constatou-se que as mulheres demonstraram serem excelentes administradoras dos recursos naturais, porém poucas participam ativamente dos processos de decisão em torno dos assuntos ambientais em âmbito local e regional; que a presença das mulheres na educação ambiental é muito importante, pois são elas que proferem a maior parte das conferências e cursos em torno das temáticas socioambientais; que tanto as mulheres como os homens são fontes de informação sobre práticas de exploração sustentável dos recursos, porém as informações, da mesma forma que suas atividades, são diferentes.

Em entrevista realizada com a coordenadora do "Programa de Innovación Agropecuária Local" (PIAL), constatou-se que as mulheres reconhecem mais a utilidade das plantas medicinais e ornamentais, a diversidade de sementes e plantação de hortas caseiras, enquanto os homens possuem maior conhecimento a respeito dos recursos florestais e atividades florestais com fins comerciais, bem como em relação à plantação de alimentos em grande escala.

\footnotetext{
${ }^{15}$ PROCEDE - Programa de Certificação de Direitos aos Ejidais (logradouros de terra apoiados pelo governo) criado em 1993 como o instrumento que daria estabilidade jurídica a terra de arrendamento.

${ }^{16}$ Publicada no Diário Oficial de la Federación (México) em 29 de agosto de 2002. Disponível em: <http:// www.conagua.com.mx>.
} 
Nos três países (Brasil, México e Cuba) ficou clara a dificuldade que ainda se mantém sobre a distribuição igualitária das tarefas domésticas, ou seja, a divisão sexual do trabalho: geralmente, o homem passa a ser incumbido das grandes decisões e o exercício decorrente do poder. Já às mulheres é atribuída e naturalizada a responsabilidade pelo cuidado dos filhos, dos anciãos e dos doentes, e as demais tarefas relacionadas à reprodução social no âmbito familiar, como demonstra a pesquisa de Lusa, realizada no contexto da agricultura familiar catarinense (Brasil):

Fica objetivo então, que a centralidade masculina tanto no que tange à posse de terra e à titularidade do acordo de integração, quanto no que se refere à administração diária do trabalho e das finanças da propriedade, concede ao homem um poder muito desproporcional àquele que a mulher exerce 'no ambiente privado', que é a residência, mesmo porque também este poder "dado" a ela por ser a "rainha do lar" nada mais implica do que responsabilizá-la pelas tarefas e pelo funcionamento do espaço de reprodução familiar.

Portanto, trabalhar com políticas públicas, programas e projetos que objetivam reduzir as brechas de equidade de gênero demanda a aplicação do enfoque de gênero em todas as ações direcionadas para o desenvolvimento. Trabalhar com o enfoque de gênero, para o Instituto Interamericano de Cooperação para a Agricultura - IICA significa considerar as necessidades e os interesses dos distintos grupos de mulheres (camponesas, indígenas, assalariadas, trabalhadoras familiares não remuneradas, jovens etc.) na formulação e na execução de políticas, projetos e programas e, ainda, ter em conta a divisão sexual do trabalho rural atualmente existente e as mudanças que estejam sendo produzidas. Significa, também, assegurar o acesso, o uso e o controle sobre os recursos produtivos (terra, créditos, capacitação, tecnologias etc.) e alterar as relações de poder, facilitando canais de participação social e política nos processos de adoção de decisões. ${ }^{18}$

Nos próximos itens, propomos apresentar e discutir como, em países do porte de Brasil, México e Cuba, são construídas as chamadas políticas públicas para as mulheres, orientadas por desenvolvimento sustentável e gênero.

\section{O Movimento de Mulheres Camponesas do Brasil - "queremos continuar no campo, produzindo alimentos e preservando a vida"}

O Brasil possui cerca de 192 milhões de habitantes (estimativa do IBGE, 2010), o que representa uma das maiores populações absolutas do mundo, destacando-se como a quinta nação mais populosa do planeta..$^{19} \mathrm{O}$ que mais preocupa é que, atualmente, $81 \%$ da população brasileira vive em área urbana e somente $19 \%$ na área rural. Esses dados revelam uma das principais preocupações do Movimento de Mulheres Camponesas; conforme depoimento de uma das entrevistadas, ${ }^{20}$ "nossa luta é para que as mulheres, juntamente com suas famílias, permaneçam no campo".

\footnotetext{
${ }^{17}$ Mailiz LUSA, 2008, p. 132.

18 IICA, 2003, p.25.

${ }^{19}$ Destes, 0,4\% são índios autodeclarados, somando cerca de 519 mil indivíduos e compreendendo uma grande variedade de tribos e nações. Por sua vez, os negros autodeclarados compõem 6,3\% da população brasileira, somando cerca de 11 milhões de indivíduos. Disponível em: <http://pt.wikipedia.org/wiki/ Demografia_do_Brasil >. Acesso: 20 set. 2010.

${ }^{20}$ Entrevista realizada com Justina, na sede do Movimento de Mulheres Camponesas, em Chapecó, no dia 21 de setembro de 2009.
} 
A trajetória de lutas do Movimento de Mulheres Camponesas (MMC) no Brasil tem início na década de 1980, no Estado de Santa Catarina, quando o país se encontrava num contexto de crise econômica e política, emergindo de um longo tempo de repressão decorrente da ditadura militar (1964 a 1985). No período conhecido como 'abertura democrática' surgiram experiências de mobilização social e contestação política, dentre as quais lutas pela terra, por moradia, por creche e outros direitos sociais que se espalhavam pelo território nacional. Ressurgiram, também, os sindicatos de trabalhadores, o 'novo sindicalismo', e vários partidos políticos de esquerda, tais como o Partido dos Trabalhadores. ${ }^{21}$

A participação das mulheres camponesas, a partir daquele período, é assinalada como uma construção política singular, com consequências que podem ser notadas, nos últimos 20 anos, tanto na esfera individual como coletiva. Na esfera individual, constata-se a construção de uma identidade 'camponesa', a conquista nos processos participativos, de autonomia, possibilidades de exercer cargos de poder e de deliberação. Na esfera coletiva, colaborando com as lutas mais amplas que possibilitaram, inclusive, a conjuntura política necessária para a transição democrática e, em seguida, para a conquista constitucional de 1988.

Nesse sentido, Kroth afirma que

A luta das agricultoras do oeste de Santa Catarina, na década de 80 , pode ser caracterizada sob três aspectos. O primeiro diz respeito à redemocratização do País, cujas marcas expressam mobilizações intensas, lutas específicas e fortalecimento de vários movimentos populares [...]. O segundo diz respeito à participação das mulheres não só nas lutas mais gerais dos trabalhadores, mas também na construção efetiva de suas lutas específicas [...]. A terceira questão colocada nesse período pelas agricultoras diz respeito à autonomia de sua organização. ${ }^{22}$

É eminente a contribuição que o Movimento de Mulheres Agricultoras teve para o aprofundamento democrático do país e para o início do processo de superação das desigualdades de gênero a partir dos anos de 1980. Pouco a pouco, através de seus trabalhos de base, as mulheres camponesas foram questionando as estruturas de dominação cultural, social e política que alicerçavam as relações sociais.

Desde seu surgimento um dos objetivos mais fortes do movimento era a conquista de direitos para as mulheres camponesas, começando pelo direito de participação efetiva nos espaços de decisão da sociedade, passando pela luta pelos direitos sociais para estas mulheres e suas famílias e chegando à luta pela autonomia e emancipação feminina, num contexto em que a cultura patriarcal e machista era regra geral. Um dos pontos fundamentais nesse processo e, talvez, o mais importante em termos de democracia representativa foi a decisão de eleger uma das militantes para atuar na esfera legislativa, a fim de dar efetividade para a conquista de direitos, pois a realidade camponesa era desconhecida e desconsiderada, pela sociedade brasileira e pelos políticos. De fato uma das militantes é eleita e, já no ano de 1987, assume uma das cadeiras na Assembleia Legislativa do Estado de Santa Catarina; logo em seguida, por dois mandatos (de 1991 a 2002), a mesma camponesa, Luci Choinacki, é eleita Deputada Federal, iniciando o período de conquistas de direitos para as mulheres camponesas no Brasil.

Três dessas conquistas são apontadas pelas camponesas em seus documentos. Em 1994, ocorre a ampliação do Salário Maternidade para as mulheres trabalhadoras rurais,

\footnotetext{
${ }^{21}$ IIse SCHERER-WARREN, 1987

22 Sirlei KROTH, 1999, p. 108.
} 
direito este antes garantido apenas para as trabalhadoras urbanas. Essa conquista é acompanhada pelo reconhecimento da profissão de 'agricultora', anteriormente reconhecida somente para os homens, permitindo-lhes, a partir disso, sindicalizar-se e acessar direitos trabalhistas na condição de 'trabalhadoras' e não mais na condição de 'dependentes' de seus esposos, pais ou filhos. A terceira conquista a ser destacada nesse estudo, conforme as entrevistas subscritas pelas autoras, refere-se ao direito à 'aposentadoria rural para as mulheres', instituída em 1995 através de Projeto de Lei da mesma militante do MMA/SC e deputada federal, Luci Choinacki.

O MMC reformula seus objetivos, bem como suas estratégias de lutas, a partir de meados do novo milênio e trabalha atualmente com três grandes áreas de lutas sociais: a questão da justa distribuição de terra para quem nela deseja viver e trabalhar; a criação, implantação e execução de políticas públicas, econômicas sociais e culturais que possibilitem o desenvolvimento da agricultura camponesa, sustentável e agroecológica; e aquela pela garantia de manutenção e efetivação de direitos já conquistados anteriormente. A atual "bandeira de luta" configurada como mensagem política do MMC/ SC é "a emancipação das mulheres camponesas e a construção da agricultura camponesa e ecológica combinadas com a luta pela transformação da sociedade". ${ }^{23}$

$\mathrm{Na} 8^{a}$ Assembleia Estadual do MMC/SC, realizada em 2001, decidiu-se pelo enfrentamento do modelo de agricultura imposta pela matriz produtiva mundial que impõem a monocultura, o uso de agrotóxicos e de sementes transgênicas que destroem a biodiversidade, buscando opções concretas para avançar no projeto da agricultura agroecológica. Desafiando o agronegócio e a lógica do capital, o Movimento assume o programa de recuperação, produção e melhoramento de sementes crioulas de hortaliças, e outras ações como o cultivo de plantas medicinais, de arvores frutíferas e nativas, proteção das fontes e nascentes de água, produção diversificada de autossustento e renda, reeducação alimentar e outras iniciativas articuladas à formação técnica e política das mulheres camponesas. ${ }^{24} \mathrm{Em}$ declaração escrita e elaborada pelo conjunto das mulheres camponesas, proferida nesse encontro, elas anunciam:

Queremos continuar no campo, produzindo alimentos, preservando a vida, as espécies e a natureza, desenvolvendo experiências de um Projeto popular para a agricultura, através: da agroecologia, da preservação da biodiversidade, do uso das plantas medicinais, da recuperação das sementes como patrimônio dos povos a serviço da humanidade, da alimentação saudável como soberania das nações, da diversificação da produção, da valorização do trabalho das mulheres camponesas. ${ }^{25}$

Entretanto, para que essas lutas possam se concretizar, o Movimento reconhece a necessidade de objetivá-las no cotidiano, incluindo também a transformação de padrões desiguais de gênero e classe, enraizados em modelos culturais, dentre os quais se destacam: a cultura patriarcal, burguesa e machista. Há que ressaltar a importância do MMC tanto em nível nacional (está organizado em 22 Estados do Brasil), quanto nos níveis estaduais, regionais e locais, para a dinâmica social, política, econômica e cultural da sociedade brasileira. Através de sua organização e de sua atuação política, esse movimento social feminista, de classe e do campo, contribui significativamente para instigar a transformação societária, minando as estruturas do sistema capitalista com suas lutas políticas e sociais.

${ }^{23} \mathrm{MMC} / \mathrm{SC}, 2008$, p. 37

${ }^{24}$ Conforme MMC/SC, 2008, p. 21.

${ }^{25}$ A Declaração completa está disponível em: <http://www.mmcbrasil.com.br/menu/historia.html>. 
Em relação aos programas de financiamento público para mulheres no campo, no Brasil, cita-se o Programa de Fortalecimento da Agricultura Familiar - PRONAF, criado em 1995 e o PRONAF - Eco (Semeando Verde), com início em 2000, ambos previstos na política de desenvolvimento da agricultura familiar do Ministério do Desenvolvimento Agrário. $O$ PRONAF tem uma linha de atendimento voltada para a 'mulher camponesa'; entretanto, funciona em patamar de desigualdade para com os homens, uma vez que o valor de crédito disponibilizado às mulheres é inferior ao valor disponibilizado aos homens e inclui uma série de exigências nos critérios de adesão como "possuir maquinário adequado" e outras que dificultam a inserção das mulheres. Além disso, por ser um programa voltado para a família, quando um membro acessa uma linha de crédito, os demais membros ficam automaticamente excluídos da possibilidade de acessá-lo naquele mesmo período. Como consequência, o que se observa é que, apesar de o governo prever a linha de crédito para as mulheres, elas acabam não a acessando, pois, conforme depoimento de uma entrevistada, acaba não sendo conveniente para a família, de forma geral.

\section{Movimento cooperativo no setor agrícola em Cuba - mulheres conquistando espaços}

Em janeiro de 1959 ocorreu em Cuba um movimento popular que derrubou o governo do então presidente Fulgêncio Batista (1952-59), considerado um ditador tirano que governava com apoio dos Estados Unidos. Até 1959, Cuba era um país com grandes desigualdades sociais e vivia sob forte influência política e econômica dos Estados Unidos. Camponeses e operários desiludidos com as péssimas condições sociais (salários baixos, desemprego, falta de terras, analfabetismo, doenças) aderiram à guerrilha liderada por Fidel Castro e Che Guevara, contribuindo para o "triunfo da revolução". A partir desta, foi implantado o sistema socialista e Fidel Castro assumiu o governo do país, tomando várias medidas, entre elas, a nacionalização de bancos e empresas, reforma agrária, expropriação de grandes propriedades e reformas nos sistemas de educação e saúde. Até hoje os ideais revolucionários fazem parte de Cuba, que é considerado o único país que mantém o socialismo plenamente vivo. ${ }^{26}$

A população cubana é atualmente de 11.217 .100 de habitantes, sendo que $37 \%$ são brancos, $11 \%$ são negros e $53 \%$ mestiços. Da população total, $74 \%$ vivem em áreas urbanas e $26 \%$ habita em zonas rurais. ${ }^{27}$

A partir do processo revolucionário, o sistema agrário cubano foi se consolidando em forma de Cooperativas. A maioria dos agricultores trabalha, atualmente, em um dos tipos de Cooperativa existentes no país: a) Cooperativa de Créditos e Serviços (CCS) inserida no setor cooperativo campesino - são "organizações associativas onde se mantém a forma individual de propriedade da terra e outros bens produtivos; o trabalho se organiza em forma de economia familiar. Esse tipo de gestão cooperativa facilita a assistência técnica, acesso à crédito e prestação de serviços às famílias de agricultores"; b) Cooperativa de Produção Agropecuária (CPA) e Unidades Básicas de Producción Cooperativa (UBPC) inseridas no setor cooperativo coletivo, que são "associações voluntárias de campesinos que unem suas terras e bens produtivos para formar uma empresa cooperativa socialista, com patrimônio comum, onde o trabalho se organiza de forma coletiva. A remuneração dos membros ocorre conforme o trabalho realizado". ${ }^{28}$

\footnotetext{
${ }^{26}$ José NAVARRO, 2000.

27 Conforme site: <http://www.campesinocubano.anap.cu>. Acesso em: 20 set. 2010.

${ }^{28}$ Conforme site: <http://www.campesinocubano.anap.cu>. Acesso em: 16 set. 2009.
} 
Em maio de 1961, no contexto do processo revolucionário, foi criada em Cuba a Associação Nacional de Agricultores Pequenos - ANAP, com a finalidade de representar os interesses das famílias de agricultores junto ao Estado. Atualmente, existem 350 mil associados nos dois tipos de cooperativas acima citadas, dos quais $11 \%$ são mulheres. A ANAP é uma espécie de mediadora entre o Estado e as cooperativas, uma vez que, "é dever das famílias integrantes das cooperativas produzir alimentos para o povo", ou seja, o Estado, através do Ministério da Agricultura (MINAGR) e do Ministério do Açúcar (MINAZ), define a política agrária. Uma vez por ano, representantes dos ministérios dirigem-se às cooperativas e definem a produção: uma porcentagem é destinada à criação de gado, e o restante à plantação diversificada de alimentos básicos como feijão, arroz, cana de açúcar, batata e outros vegetais. Ao final da colheita, compram a maioria da produção para distribuir nos "puestos de abasto" para o povo. Segundo a coordenadora da ANAP, ${ }^{29}$ atualmente, há uma crescente preocupação da entidade em valorizar o trabalho feminino junto às cooperativas agrárias, conforme metas da sucursal de Havana para 2010, que é incorporar 100 mil cubanas na Associação. Em relação à produção agroecológica, a ANAP tem apostado no Movimento agroecológico que aos poucos se "converte em um movimento político de massas". ${ }^{30}$ Uma das Cooperativas de Produção Agropecuária (CPA), atualmente, tem capacidade para elaborar 400 toneladas anuais de biofertilizantes e bioinseticidas, tanto para fins nacionais como para exportação.

Existem também, em Cuba, programas apoiados por ONGs do exterior, como é o caso da "Welthungerhilfe / Agro Acción Alemana", que há 15 anos desenvolve o Programa de Innovación Agropecuária Local (PIAL) em parceria com o Instituto Nacional de Ciências Agrícolas (INCA). Esse programa tem como objetivo fortalecer um sistema de inovação agropecuária em Cuba, estimulando a incorporação da diversidade a favor do meio ambiente. É dirigido a mais de 4.000 camponeses e suas famílias de diferentes formas organizativas, em 10 províncias do país e indiretamente à população que vive ao redor das fazendas, para uma melhor oferta alimentícia local. A partir de 2008, a equipe de técnicos envolvidos nesse programa tem adotado o enfoque de gênero como eixo transversal em suas abordagens comunitárias, motivando as mulheres a aderirem à proposta de desenvolvimento sustentável. Em fôlder distribuído pelo programa consta que "promover a equidade de gênero significa reconhecer que mulheres e homens possuem necessidades e prioridades distintas, enfrentam distintos tipos de obstáculo, possuem distintas aspirações, porém, a partir dessas diferenças contribuem 'por igual' ao desenvolvimento da sociedade". ${ }^{31}$

Participando de uma Feira de produtos agropecuários, ${ }^{32}$ constatamos que um grupo de mulheres já havia se incorporado ao "Programa de Mejoramiento Genético de Semillas" desenvolvido pelo INCA; expunham seus produtos sem agrotóxicos e uma variedade de sementes que tinham sido cultivadas com apoio e agora colhidas, para realizar uma troca entre os agricultores locais.

Apesar dessas iniciativas pioneiras, constata-se, de modo geral, que ainda há pouca participação das mulheres no sistema de cooperativas. Pesquisando sobre a inserção feminina em organizações agropecuárias em 12 províncias de Cuba, a investigadora

\footnotetext{
${ }^{29}$ Entrevista realizada pelas autoras, com a coordenadora da ANAP, Rosário Martinez, na sede da ANAP, Plaza de la Revolución, Havana, Cuba, em 29 de outubro de 2009.

${ }^{30}$ Fala da coordenadora da ANAP, Rosário Martinez, em entrevista concedida às autoras.

${ }^{31}$ Fôlder "Hablando de Género", distribuído pelo Programa de Innovación Agropecuária Local - PIAL.

${ }_{32}$ Visita realizada em 22 de outubro de 2009, a convite da coordenadora do Programa de Innovación Agropecuária Local (PIAL), Dagmara Plana Ramos. Na ocasião, ocorria a II Feira de produtos agropecuários da região, localidade de Cerro Largo, província de Havana, e fomos recebidas pela técnica agrícola Bárbara Benitez, que também nos concedeu entrevista.
} 
Niurka Pérez Rojas ${ }^{33}$ constatou que o trabalho realizado por esposas de camponeses fora do lar é escasso. A maioria dos proprietários de terra considera essencial e necessário que as mulheres atendam ao trabalho doméstico, aos filhos e aos anciãos enfermos. Um número significativo de homens entrevistados expressou estar em desacordo com a participação da mulher no trabalho produtivo e outros opinaram que as tarefas agrícolas são muito pesadas para as mulheres. Esses depoimentos refletem que a participação das mulheres é vista de forma desvalorizada e é qualificada na divisão sexual do trabalho como tarefa "de menor esforço", situando-a na esfera da "ajuda". As mulheres entrevistadas consideram que o motivo fundamental de sua não incorporação nas cooperativas é a obrigação de atender ao trabalho doméstico e não possuir uma imperiosa necessidade econômica nem social. Apesar disso, sentem-se limitadas no que diz respeito à tomada de decisões em relação aos trabalhos na agricultura, bem como na obtenção de financiamentos para qualquer iniciativa.

Com o objetivo de canalizar os interesses das mulheres do campo e da cidade, foi criada, em 23 de agosto de 1960, a Federação das Mulheres Cubanas (FMC). Essa Federação possui 14 direções provinciais, 169 direções municipais e 76 mil delegações de base em todo o país. Segundo a dirigente da Federação, Tamara Colombieri, ${ }^{34} 4$ milhões e 200 mil mulheres fazem parte, atualmente, da Federação. A partir dos 14 anos de idade, as adolescentes já podem inscrever-se, pagando uma anuidade de três pesos cubanos. Os principais objetivos da Federação, que constam nos documentos de sua fundação (1960), são: erradicar o analfabetismo em Cuba; proporcionar atendimento de saúde de qualidade para mulheres e crianças; garantir educação básica de no mínimo nove anos de estudo para todas as meninas; oportunizar emprego para as mulheres com fins de tornálas independentes; trabalhar na perspectiva de empoderamento das mulheres para que possam ocupar posições de direção. Com apoio da FMC, foram criados, em todo o país, tanto nas zonas rurais como urbanas, os "Círculos de idosos" e os "Círculos infantis" para garantir atendimento a estes segmentos, durante o dia.

Ao serem indagadas sobre a existência de um movimento específico de mulheres do campo, duas representantes da Federação das Mulheres Cubanas, ${ }^{35}$ residentes em área rural, responderam que a Federação, através da sua delegação de base, está constantemente preocupada em saber quais as demandas das mulheres e atendê-las; que a Federação já representa um movimento de mulheres. Em relação à participação das mulheres junto às Cooperativas, afirmaram que ainda é insípida, que as mulheres realizam tarefas consideradas femininas como secretariar as reuniões, cozinhar durante as assembleias e outras. Possuem clareza de que os jovens, de maneira geral, estão deixando o campo e migrando para as cidades, atraídos por melhores condições de vida, para continuar os estudos em uma universidade e seguir em busca de oportunidades de trabalho. As mulheres entrevistadas encerraram suas falas dizendo que um dos problemas que a revolução cubana não conseguiu eliminar é o machismo e a violência doméstica.

\footnotetext{
${ }^{33}$ Entrevista realizada pelas autoras, na residência da Professora de Sociologia Agrária da Universid de Havana, Niurka Perez Rojas, Havana, em 24 de outubro de 2009.

${ }^{34}$ Entrevista realizada pelas autoras, na sede da Federação de Mulheres Cubanas, Havana, em 27 de outubro de 2009.

${ }^{35}$ Entrevista realizada em 22 de outubro de 2009, em uma Feira de produtos rurais realizada na localidade de Cerro Largo, na província de Havana.
} 


\section{Mulheres indígenas, campesinas e fluxos migratórios para os Estados Unidos - a situação no campo mexicano}

México é um país que, dos seus 100 milhões de habitantes, $20 \%$ é formado por populações indígenas que sobrevivem trabalhando no campo (plantando milho e feijão), ou produzindo e vendendo artesanato na cidade. Segundo dados do Instituto Nacional de Estatística, Geografia e Informática de México (INEGI), de 2005, dos 9,5 milhões de pessoas indígenas que vivem no México, 51 \% são mulheres. O reconhecimento de determinados direitos dos povos indígenas, como acesso ao desenvolvimento, aceder plenamente a jurisdição do Estado, preservação da identidade cultural, garantia de acesso a terra, a consulta e participação, só ocorreu na Constituição mexicana de 1992, e teve como antecedente o levantamento do Exército Zapatista de Libaración Nacional (EZLN), no Estado de Chiapas.

Pouco mais da metade da população indígena vive em regiões rurais, a maioria na região sul e sudeste do território mexicano, onde se concentram os mais altos níveis de pobreza e a maior quantidade de municípios considerados marginalizados, do país.

Em estudo realizado pela Rede Nacional de Promotoras e Assessoras Rurais (Redpar) no contexto de 15 de outubro, "Dia Internacional da Mulher Rural", ${ }^{36}$ publicado como "Diagnóstico sobre o Impacto da Crise Alimentar Mundial das Mulheres Indígenas e Camponesas" (2008), ficou constatado que o aumento nos preços dos grãos básicos (milho, feijão), a liberação do mercado e a dependência alimentária impedem que as mulheres camponesas e indígenas possam comercializar seus produtos adequadamente. O mesmo estudo conclui que o Estado não vê as mulheres que trabalham no campo como sujeito de direitos nos programas sociais e não lhes proporciona acesso à informação sobre os programas e financiamentos, oferecidos pelas instituições governamentais, que possam vir a beneficiá-las. Aliado a esse fator está o agravante de que as terras das famílias que vivem na zona rural estão cada vez mais demandadas pelas agroindústrias e urbanizadores, o que afeta de modo especial as mulheres: por não serem titulares das terras, não são consultadas sobre a sua venda. Em função do alto fluxo migratório para os Estados Unidos, principalmente dos homens (marido e filhos), as mulheres permanecem no campo, assumindo uma jornada de trabalho diário, que varia entre 14 a 18 horas. Apesar de representarem $25 \%$ dos 4,5 milhões de titulares de terra no campo, a venda das terras na zona rural tem sido um problema que preocupa as mulheres, pois a maioria das terras permanece como propriedade legal dos maridos, pai, sogro; portanto são eles que decidem quando querem vender. Há famílias que vendem as terras para pagar os custos da emigração para os Estados Unidos; em outros casos, fazendeiros ou narcotraficantes se apoderam de forma violenta das terras e há maridos que vendem as terras e partem deixando as mulheres e filhos sem nada.

Conforme Guadalupe Cruz James, ${ }^{37}$ as mulheres camponesas no México, por sua condição de pobreza, de dupla, tripla jornada de trabalho, encontram-se em maiores condições de subordinação e discriminação em suas comunidades e no país em geral, mostrando claramente que as políticas sociais não contemplam suas necessidades. Um

\footnotetext{
${ }^{36} \mathrm{O}$ dia 15 de outubro como "Dia Internacional das Mulheres Rurais" tem sua origem na Conferência de Beijing (1995) organizada pela ONU, como resultado das reivindicações da Federação Internacional de Produtores Agrícolas - FIPA, da Rede de Associações de Mulheres Campesinas Africanas - NARWA, e da Fundação "Cumbre Mundial de la Mujer" - FCMM. A ONU reconheceu essa data em 2008.

${ }^{37}$ CRUZ JAMES, 2009.
} 
exemplo é o Programa Oportunidades, ${ }^{38}$ uma transferência econômica destinada para as mulheres rurais em troca da prestação de um serviço, como limpar uma clínica ou consultório em Posto de Saúde, varrer a praça pública, ou assistir a reuniões de cunho político. Ao passo que o Procampo ${ }^{39}$ é dirigido aos homens sem a exigência de que realizem uma atividade em troca. Esse fato resulta em "humilhação" para as mulheres.

Em palestra proferida no Instituto Nacional de Nutrição, ${ }^{40}$ a investigadora Blanca Rubio ressaltou que as mulheres reclamam que o Programa Oportunidades está eximindo os homens de suas responsabilidades, uma vez que somente elas assumem os gastos da unidade doméstica. As mulheres camponesas reivindicam que sejam reconhecidas como produtoras e não como pobres, que lhes seja outorgado crédito e mais recursos para o campo, para poderem viver da agricultura. Nesse mesmo evento, a indígena nahua, Brígida Chautla, integrante da "Asociación Mexicana de Mujeres Organizadas em Red Via Campesina", afirma que "o campo não é considerado uma prioridade para o governo, menos ainda os povos indígenas; por isso, sua participação na organização das mulheres rurais é a melhor forma de exigir do governo políticas includentes". ${ }^{41} \mathrm{Em}$ relação à valorização da cultura e alimentação local mencionou: "a preocupação das mulheres campesinas é manter o nosso modo de vida, herdado dos antepassados, poder viver da terra, assegurar a alimentação que nós mesmas produzimos, porque o governo diz que assegura a alimentação trazendo produtos do estrangeiro, isso é ser dependente, quando isso se pode fazer em nosso país".

Em estudo feito pelo Instituto Interamericano de Cooperação e Agricultura (IICA) sobre "A Experiência Mexicana das Mulheres no Desenvolvimento Rural" (2003), constatouse que a feminização da agricultura é um fenômeno presente em várias regiões do México e, de maneira particular, cresce o número de mulheres proprietárias de terra, devido ao incremento dos índices de migração dos homens em busca de emprego, principalmente nos Estados Unidos. Aumenta, portanto, a importância da condição e da posição das mulheres na produção agropecuária, na segurança alimentar, na reprodução da economia camponesa e na transformação da qualidade de vida no meio rural.

No México existem experiências significativas que já incluem a perspectiva de gênero como a Asociación Mexicana de Mujeres Organizadas en Red, Asociación Civil (AMMOR, A.C.) - uma organização que integra grupos e organizações de mulheres, locais e regionais, tanto no âmbito rural como urbano, que buscam a equidade de gênero, bem como o fomento, a autonomia e a pluralidade; desenvolvem o "Programa de formación de promotoras campesinas para el desarrollo agrário" em parceria com a Secretaria de Reforma Agrária,

${ }^{38}$ O "Programa Oportunidades" é um programa federal, criado no México em 1997, com a missão de coordenar ações interinstitucionais para contribuir para a superação da pobreza, mediante o desenvolvimento das capacidades básicas das pessoas e acesso a melhores oportunidades de desenvolvimento econômico e social. Oferece apoio na área da educação, saúde, nutrição e salários. Participam do Programa, a Secretaria de Educação, a Secretaria de Saúde, o Instituto Mexicano de Seguridade Social, a Secretaria de Desenvolvimento Social e os governos estatais e municipais. Disponível em: <http://www.oportunidades.gob.mx>. Acesso em: 9 jul. 2010.

39 O "Programa de Apoyos Directos al Campo" - PROCAMPO foi implementado no México em finais de 1993 e surge como um mecanismo de transferência de recursos para compensar os produtores nacionais pelos subsídios que recebem seus competidores estrangeiros com base no esquema de preços de garantia dos grãos e das plantas oleaginosas. Disponível em: <http://www.e-mexico.gob.mx>. Acesso em: 9 jul. 2010.

${ }_{39}$ Palestra proferida no Instituto Nacional de Nutrición/UNAM (DF, México), em 18 de setembro de 2009.

${ }^{40}$ Depoimento pessoal de Brígida Chuatla, obtido durante o Evento sobre Segurança Alimentar, no Instituto Nacional de Nutrición/UNAM, em 18 de setembro de 2009.

${ }^{41}$ Depoimento pessoal de Brígida Chuatla, obtido durante o Evento sobre Segurança Alimentar no Instituto Nacional de Nutrición/UNAM, em 18 de setembro de 2009. 
formam lideranças e incentivam a participação política e econômica das mulheres, incorporando a perspectiva de gênero como eixo transversal em suas diferentes áreas de intervenção. Atualmente, a AMMOR agrupa mais de duzentas organizações regionais e locais de mulheres entre Associações Civis, Sociedades de Solidariedade Social, Sociedades Cooperativas, Sociedades de Produção Rural, Unidades Agroindustriais de Mulheres e Grupos de Trabalho, somando em conjunto aproximado de 7.000 sócias, distribuídas em 15 Estados da República. ${ }^{42}$

Na região de Chiapas, o Estado com maior número de povos indígenas, foi implantado o "Programa de Apoyo a la Mujer", ${ }^{43}$ com o propósito de incentivar e capacitar lideranças junto às mulheres campesinas, na defesa dos seus direitos econômicos e sociais, apoiando sua autonomia organizativa e potencializando suas iniciativas produtivas. O programa prevê, ainda, a geração de espaços de interlocução com as instâncias de gestão dos recursos naturais em nível local e regional, para negociar demandas e propostas, ou seja, que as mulheres ajudem na conservação e restauração dos recursos naturais, ampliando assim seus níveis de bem-estar e qualidade de vida. Destacam-se, também, nessa região, um número significativo de organizações indígenas produtoras de café comercializado nas redes mundiais de Comércio Justo. ${ }^{44}$

Para o grupo do IICA, (2003), trabalhar com a perspectiva de gênero no México implica alcançar uma melhor equidade na distribuição da renda, um melhor balanço inter-regional e intersetorial, um impacto direto e sustentável na pobreza rural e um acesso mais amplo a serviços básicos e bens públicos. Em primeira instância, a experiência tem demonstrado que a unidade básica para o desenvolvimento integral é a família. Partindo desse marco, é necessário: a) gerar alternativas para que as famílias rurais incrementem sua capacidade de geração de riqueza e sua inclusão na economia geral do país, obtendo uma melhor qualidade de vida no meio rural; b) inserir os jovens e as mulheres na configuração da sociedade rural $[\ldots]^{45}$

Pode-se afirmar que as novas gerações de mulheres campesinas, no México, ao adentrarem no século XXI, estão tendo mais oportunidades para capacitar-se e engajar-se em lutas pelo acesso aos direitos do que suas predecessoras. Elas possuem melhores condições de saúde, de educação e suas cargas de trabalho no campo e no espaço doméstico já estão mais equilibradas. Apesar de ainda suportarem a dominação masculina nesses âmbitos, à raiz de novas experiências pelas quais passam no cotidiano, estão tomando consciência de suas próprias capacidades e restrições, têm questionado sua falta de autonomia e reconhecido o excessivo controle masculino no espaço privado.

\footnotetext{
${ }^{42}$ Dados obtidos através de entrevista realizada pelas autoras, com a coordenadora da AMMOR, na sede da ONG, localizada na Colonia Vista Alegre, DF, México, em 12 de outubro de 2009.

${ }^{43}$ Documento produzido pela ONG Promujer, San Cristóbal de las Casas, Chiapas (México). Consultar: <http:promujerchiapas@prodigy.net.mx>.

${ }^{44}$ Comércio Justo é um comércio diferente, embasado na justiça social, qualidade do produto e o cuidado com a natureza. Fomenta uma vinculação direta entre produtores e consumidores e contribui para a construção de um modelo de desenvolvimento sustentável. Para maiores detalhes, consultar <http:// www.comerciojusto.com.mx> e também <http://www.comerciojusto.com.br>.

${ }^{45}$ IICA, 2003, p. 51.
}

884 Estudos Feministas, Florianópolis, 16(3): 871-887, setembro-dezembro/2010 


\section{Refletindo sobre as semelhanças e diferenças entre os três países (Brasil, Cuba e México)}

Os princípios que orientam o modo de produção e organização da sociedade, seja ela capitalista ou socialista, configuram-se com as bases que fundamentam a concepção de políticas sociais. Um dos aspectos fundamentais diz respeito à própria concepção de 'bem-estar social'. Segundo a investigadora Maria Auxiliadora César, em uma sociedade socialista,

el bienestar es concebido como una norma social basada en valores de cooperación y de solidaridad; se manifiesta concretamente en el reconocimiento de la existencia de necesidades humanas, o sea, es central la idea de una sociedad, de un modo de producción y de distribución de los recursos basados en la satisfacción de las necesidades humanas. $^{46}$

Por sua vez, os elementos do modo de produção capitalista são:

la propiedad privada sobre los medios de producción; la producción para el lucro; la propiedad privada y la herencia; la asignación de los ingresos y recursos a través del mecanismo de mercado, y el dominio del mercado niega necesidades y solidaridad. ${ }^{47}$

Constata-se através da análise feita pela autora que, em ambos os modos de produção, o princípio de bem-estar social refere-se ao atendimento das necessidades básicas, o que se dá no socialismo a partir do fundamento da igualdade e, no capitalismo, pelo fundamento da lucratividade econômica.

Em relação às necessidades básicas, Potyara Pereira ${ }^{48}$ identifica, além da alimentação, moradia, saúde e proteção social, outras que estão relacionadas ao reconhecimento de toda uma gama de quesitos indispensáveis para a vida em sociedade: as necessidades de educação, cultura, liberdade, existência de condições adequadas para pensar, refletir, optar, decidir, tão aspiradas pelas mulheres do campo.

A pesquisa mostrou que, nos três países, as mulheres possuem um papel preponderante na gestão dos recursos naturais devido a sua responsabilidade na provisão de alimentos para o sustento da família. Tanto no cultivo como na coleta de frutos, raízes, lenha, ervas e plantas medicinais, forragem para os animais, ramos e folhagens para o forro e a construção de suas casas, cuidado com a água, todas essas atividades requerem um aguçado conhecimento dos ecossistemas circundantes e das peculiaridades dos ciclos naturais. Além disso, elas contribuem para manter a diversificação e associação dos cultivos, semeadura, manejo integrado de pragas, conservação do solo, proteção e aproveitamento de plantas com fins nutricionais, medicinais, sanitários e econômicos. Através de seus conhecimentos contribuem como usuárias e como gestoras de todo um sistema de biodiversidade e agroecologia.

Por esse motivo, as pequenas propriedades rurais deveriam ser consideradas e valorizadas como um lugar no qual se desenvolvem um conjunto de atividades produtivas e reprodutivas. As produtivas são aquelas que geram diretamente um ingresso, seja de produtos em espécie, seja monetário: comercialização de alimentos ou trabalho assalariado. As atividades reprodutivas são aquelas que contribuem para manutenção e reprodução da força de trabalho, também denominadas de atividades domésticas. Pontua-se, ainda, uma terceira categoria que se refere às atividades de gestão comunitária, na qual as

${ }^{46}$ Maria Auxiliadora CÉSAR, 2005, p. 137.

${ }^{47}$ CESAR, 2005, p.137.

${ }^{48}$ PEREIRA, 2000, p. 76. 
mulheres também se destacam, destinadas a fazer funcionar a trama comunitária, processos sócio-organizativos, destinados a reivindicar políticas públicas, gerar serviços básicos, apoio mútuo, solidariedade em relação ao 'que fazer' cotidiano e administrar situações de crise. Expressa-se nessa categoria de atividades a atuação política das mulheres que, por vezes, chega também à participação política partidária, como foi o caso da camponesa catarinense que se tornou parlamentar por três mandatos políticos sucessivos.

Algo que ficou evidenciado nos três países foi a dificuldade em relação à divisão igualitária das tarefas domésticas e às correspondentes ao cuidado das crianças, idosos e doentes. Com isso, podemos constatar que a revolução cubana colocou ênfase na igualdade de classes fundamentada no princípio da justiça social, porém ainda não conseguiu superar a desigualdade de gênero, que permanece enraizada nos valores tradicionais do patriarcado.

Por último, deixamos como questionamentos e reflexões: quais seriam as principais demandas e necessidades reivindicadas pelas mulheres do campo atualmente: o direito ao título de propriedade e à posse da terra, às políticas de crédito, ou maior valorização e reconhecimento de seu trabalho e de seu protagonismo nas lutas sociais? Como engajarnos no processo em direção a um desenvolvimento sustentável com perspectiva de gênero?

\section{Referências bibliográficas}

CÉSAR, Maria Auxiliadora. Mujer y política social en Cuba: el contrapunto socialista al bienestar capitalista. Habana, Cuba: Mercie Ediciones, 2005.

CRUZ JAMES, Guadalupe. México: vivir de la agricultura, piden mujeres rurales. Disponível em: <http://www.gloobal.net>. Acesso em: 8 jul. 2009.

IICA - INSTITUTO INTERAMERICANO DE COOPERAÇÃO PARA A AGRICULTURA. Seminário Internacional: "Gênero no desenvolvimento sustentável dos territórios rurais". Documento Síntese. Natal, RN, 2003

KROTH, Sirlei Antoninha. Atalhos da luta: trajetórias e experiências das mulheres agricultoras e do Movimento de Mulheres Agricultoras de Santa Catarina 1983-1993. 1999. Dissertação (Mestrado em História) - Programa de Pós-Graduação em História, Universidade Pontifícia Católica de São Paulo.

LAGARDE, Marcela. Gênero y feminismo - desarrolo humano y democracia. Madrid: Horas \& Horas, 1996.

LUSA, Mailiz Garibotti. Trabalho no contexto rural: quando a divisão sexual do trabalho conforma as tramas da identidade de mulheres e homens da agricultura familiar no Oeste Catarinense. 2008. Trabalho de Conclusão de Curso de Serviço Social - CSE/DSS, Universidade Federal de Santa Catarina, Florianópolis.

MAX-NEEF, Manfred; ELIZALDE, Antonio; HOPENHAYN, Martín. Desarrollo a Escala Humana uma opción para el futuro. Chile: Cepaur \& Fundación Dag Hammarskjöld, 1986.

MAX-NEEF, Manfred. "'Empoderamento' de comunidade e desenvolvimento alternativo". Pedagogia Social Artigos. Associação de Pedagogia Social de Base Antroposófica do Brasil, Boletim n. 17, abr. 2003. Disponível em: <http:www.pedagogiasocial.com.br>. Acesso em: 11 fev. 2008.

MMC/SC - MOVIMENTO DE MULHERES CAMPONESAS DE SANTA CATARINA. Movimento de Mulheres Camponesas em Santa Catarina. Uma história de organização, lutas e conquistas. Chapecó: MMC/SC, 2008.

NAVARRO, José Cantón. História de Cuba - el dasafío del yugo de la estrella. La Habana: SiMar S.A., 2000. 
PEREIRA, Potyara A. P. Necessidades humanas: subsídios à crítica dos mínimos sociais. São Paulo: Cortez, 2000.

ROCHELEU, Dianne; THOMAS-SLAYTER, Barbara; WANGARI, Esther. "Género y ambiente: uma perspectiva de La ecologia política feminista”. In: GARCÍA, Verónica Vázquez; GUTIÉRREZ, Margarita Velázquez (Comp.). Miradas al futuro - hacia la construcción de sociedades sustentables con equidad de género. México: Programa Universitario de Estudios de Género (PUEG); Universidad Nacional Autónoma de México (UNAM); Instituto de Socioeconomía, Estadística y Informática (ISEI); Centro Internacional de Investigación para el Desarrollo (CRDI), 2004. p. 343-371.

SACHS, Ignacy. Desenvolvimento includente, sustentável, sustentado. Rio de Janeiro: Garamond, 2008.

SCHERER-WARREN, Ilse. "O caráter dos novos movimentos sociais". In: SCHERER-WARREN, Ilse; KRISCHKE, Paulo J. (Orgs.). Uma revolução no cotidiano? Os novos Movimentos Sociais na América do Sul. São Paulo: Brasiliense, 1987.

SHIVA, Vandana. "O empobrecimento do ambiente: as mulheres e as crianças para o fim". In: MIES, Maria; SHIVA, Vandana. Ecofeminismo. Lisboa: Instituto Piaget, 1993.

[Recebido em setembro de 2010 e aceito para publicação em outubro de 2010]

\begin{abstract}
Sustainable Development from a Gender Perspective - Brazil, Mexico, and Cuba: Women as Protagonists in Rural Areas

Abstract: This article discusses different views about sustainable development, emphasizing on the basis of a survey conducted in Brazil, Mexico, and Cuba - the role of rural women in food production and natural resource management, the strength of the rural women's movement in the conquest of rights, and the decisive participation of women in defining proposals for public policies that guarantee gender equality in rural areas. A brief comparative analysis leads us to conclude that the development model in the three countries still prioritizes the male figure in relation to land tenure, access to credit and purchase of equipment or other material resources. It is suggested that both in Cuba, a socialist country, and in Mexico and Brazil, capitalist countries, the assumptions of social policies directed to rural female workers should take into account the basic needs of rural women to guarantee a more humane and sustainable development.
\end{abstract}

Key words: Gender and Environment; Sustainable Development; Social Policies; Basic Needs. 